\title{
Kin Kam: resilience and enlightenment
}

Steve Chaplin

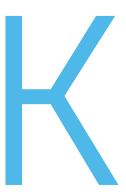

in $\mathrm{F} \mathrm{Kam}$ is an inventor and writer who has severe haemophilia A. Born in Hong Kong in 1967, at age ten he came to the UK with his mother and two brothers to join his father, who had established a successful fish and chip shop in Oldham, Greater Manchester. He went on to academic success at university, obtained a doctorate and followed a career in research before going on to develop and market his inventions. All this he recounts in his autobiography Blood, Dragons \& Lions.

So far, so impressive. But Kin lived with the challenges of having haemophilia and being an immigrant from a minority ethnic group - a double dose of difference that weighed heavily on a child growing up in the North West of England during the '70s and ' 80 s. The experience of coping with haemophilia and the associated stigma was so traumatic that he couldn't bring himself to use the word throughout most of his book, referring to his condition only as ' $\mathrm{H}$ '.

"I think later on in my book I start to say that I don't care so much now. I've started to work on the word."

Kin's accounts of the racism prevalent at the time - which would unwittingly emerge in occasional comments in later years - reveal how society's selfproclaimed tolerance and fairness did not reach very deep into the national psyche. But he says haemophilia is still harder to deal with:

STEVE CHAPLIN

Haemnet, UK. Email: steve@haemnet.com

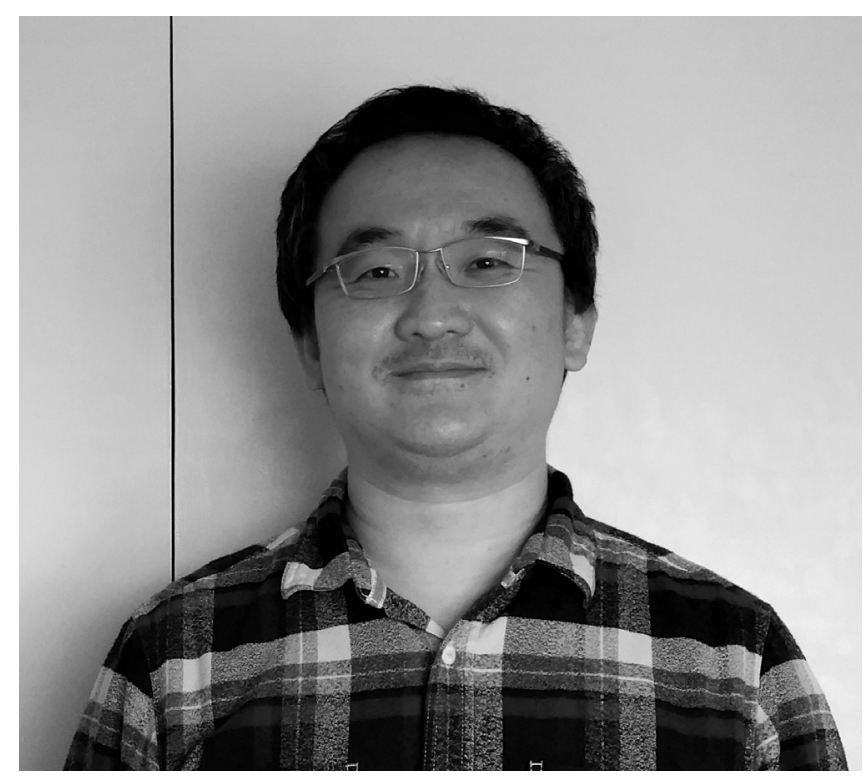

A successful inventor and writer, Kin Kam has struggled to cope with his haemophilia throughout his life. However, he believes that this struggle and the self-realisation that goes with it has ultimately empowered and enlightened him

"...actually, to be quite frank, the racist element, the racial prejudices... I just feel like everyone else in my situation... It's almost not unusual. Whereas the haemophilia side, haemophilia makes me feel much more different to everyone else, and it's a hidden disability as well... the haemophilia side is the bit where I feel it's most difficult to talk about or deal with.."

And he certainly spent much of his childhood denying the full reality of haemophilia. In Hong Kong and the UK, he would do his utmost to spare his mother the truth about injuries from falls, fights and school punishment. This meant he denied himself replacement factor until it was unavoidable. He writes:

This is an Open Access article distributed under the terms of the Creative Commons Attribution-NonCommercial-NoDerivs License (https://creativecommons.org/licenses/by-nc-nd/3.0/) which permits use and distribution in any medium, provided the original work is properly cited, the use is non-commercial, and no modifications or adaptations are made. Copyright is retained by the authors. 
"I had developed a masochistic desire to defy my $H$, to show the world I could live normally without special medication... In some sense, I'm glad of my ignorance when I was younger and the way I perceived my rebellion against haemophilia. But it has done damage to my joints more than if I'd listened to the medical people."

But he would suffer spectacularly when, aged 11, a misstep while practising a martial arts move caused a bleed in his hip, already a target joint. He ignored it for several days, all the while going to school and hoping it would get better by itself:

"As was normal for the assembly, pupils sat on the ground, legs crossed as they listened to the teachers. I recall forcing myself into that position despite the then intensely tensed, inflamed and swollen hip. The pain I endured in those minutes was just completely beyond anything that I have ever felt."

Kin was eventually admitted to hospital, when it was discovered that bleeding had spread into the psoas muscle, compressing his femoral nerve. He remained there for about three months, followed by months of physiotherapy as he relearned how to walk. Muscle wasting also exacerbated problems with his knee, another target joint, and left him with a limp.

"I accepted I'd got a problem, no doubt about it, but it was just something that was ingrained in me. Any other reason why I didn't want to treat myself? Well, obviously, I don't want to stand out like I'm some kind of saint or something, but I didn't want to trouble my parents. So, that's why I'd hide my troubles; I wanted to protect them from knowing I'm in pain or whatever. I didn't want them to worry."

Stoicism is a trait the Chinese and British share, Kin says, and in him it built resilience:

"I'm fighting battles from birth, almost every day. So, I have that feeling of... I mean, I've gone through a lot, suffered a lot, like a boxer who has to fight every week."

But it was still easier to not to acknowledge haemophilia to employers and work colleagues. Kin left his first research post to do a PhD, partly because he had had enough of the routine - but often self-imposed - pressures of employment. He says haemophilia had probably burned him out.

"I'm not complaining. Where I worked, the people and the working conditions were really good. I didn't have to really explain myself or anything. But sometimes l'd just kind of take days off as holiday because I didn't want to be perceived as being off sick."

It wasn't until, in his thirties, he developed persistent problems with his ankles in his next job that he eventually told his boss he had haemophilia. Kin says it came as a big relief, though he was approaching the end of his contract and possibly felt he had little to lose. So what does he imagine other people think about living and working with a person who has haemophilia?

\begin{abstract}
"It depends on how sympathetic that person is. For example, I've got two other brothers; they're normal - but I never speak to them about my haemophilia. But they never ask. I don't think they're interested... I think with some individuals, they're more sympathetic and then they could maybe make more allowances. That might have come through them having some other experience through illness or whatever. Otherwise, I think most ordinary, lucky, normal people, I don't think they think much about it."
\end{abstract}

He now says he wishes he had been more open with everyone. Kin's experiences have persuaded him that it's essential to treat a bleed immediately and aggressively. Perversely, there was one immeasurable benefit from his reluctance to have treatment: his low exposure to clotting factor during the 1980s meant he did not contract HIV.

He did, however, get hepatitis $C$ and this caused further stigmatisation. Diagnosed in his teens, he did not realise that the fatigue he struggled with during his A-levels was probably caused by the infection, gaining this insight years later only after talking to others in the same situation. Romantic relationships were difficult for many years because he did not want to reveal the diagnosis to potential girlfriends. The virus was eventually cleared by treatment in 2007.

This was a part of Kin's life, but not all of it. He became a biker and joined a local club - not what many people would call a safe pastime. In truth, 


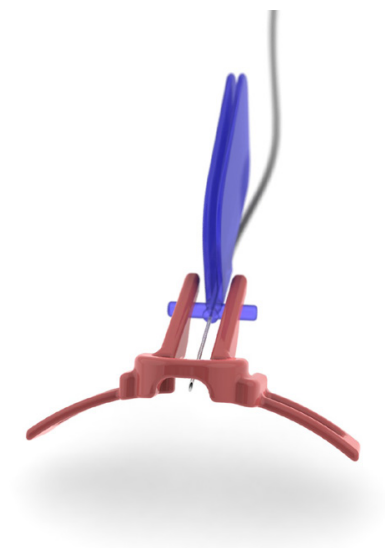

As an inventor, Kin Kam is naturally drawn to finding solutions to issues that he encounters. His inventions include a device designed to help make IV infusions easier by controlling the angle of the needle as the skin is punctured, guiding it into the vein

enjoying motorcycling is about managing risk and keeping a steady head and a clear mind. It's a lot safer than non-bikers think and the discipline needed to ride safely had a knock-on effect on Kin's thinking about his haemophilia. He had been laissez-faire about prophylaxis but, every Saturday morning before the club run, he'd be sure to have an infusion.

Never one to shy away from a challenge, Kin became an inventor and has spent years striving to develop his ideas (he now has five patents for consumer and medical devices to his name). As with others like him, he felt a natural inclination to create solutions to dilemmas he encountered. One came from his dislike of needles and injections:

"I'm aware of it all the time. I try my best to be more... My condition, really, it should be three times a week, but I still average once, maybe even twice a week... Or even when I feel good, once a week is a good compromise if I'm lucky enough..

"To be quite frank, treatment now is virtually safe - there's nothing to worry about. If it was a tablet, I'd do it. If I could do it at an exact time every day, on the hour, three times a day, I'd do it. But it's the injection. That creates a lot of inertia and hesitation. And also, injections, that's why I'm a bit concerned... it's me overthinking, you know, I've got to protect my veins. It's stupid, isn't it? But sometimes, if I've only got one vein to do it, I'm a lot more protective."

This led Kin to develop an IV injection aid to try to make infusions easier. The device controls the angle of the needle after the skin is punctured, guiding it into the vein. This is a practical example of how haemophilia has influenced his life, but the impact on his career has been more subtle because at times the bleeding disorder affected his focus and ability to think clearly:

“...the haemophilia side has actually very much guided my career path, first in the way that it affected my life - so, in my previous, more conventional job career. Haemophilia has always been part of it. Instead of thinking about work I was doing, whatever job I was doing, because of a bleed or whatever I was thinking about the pain, 'What am I going to do tomorrow? Do I have to take a day off?' So, it actually distracted me a lot. If I hadn't had it, my mind might have worked differently and been more focused. So, the haemophilia has always guided my career."

It has also shaped his outlook on life in the most profound way. In his mid-twenties, Kin was experiencing repeated episodes of severe, disabling pain in his right knee that resulted in several admissions to hospital. On one occasion, after days in bed recovering, he gained an insight that, in his words, transformed his life. He was, by nature, sceptical and doubtful of religion and some of the benefits attributed to it, but had lately been listening to the teachings of a guru whose inclusive and good-humoured approach he found appealing. He realised that his years of enduring and thinking about severe pain and disability was a form of deep focused internal devotion. He writes:

\section{"As soon as I realised that, I felt a tide of calmness, joy and elation wash over me. Perhaps this is what it felt like to be enlightened."}

Now he knew that neither God nor the supernatural were required for enlightenment: self-realisation was a feeling of heightened awareness that came with full understanding of something profound:
"...It was a real feeling. It's not some kind of mad, drug-induced experience... It's purely because you force yourself to consider a lot of things for a long, long, long time. It's just like any other great skill you might develop - you have to put yourself in it."

This wasn't a transient effect - the awareness of elation lasted for months and there has been a permanent change for the better in the impact of his haemophilia: 
"...the other great thing that kind of confirmed that something special had happened was my knee wasn't causing... I wasn't getting frequent bleeds and it really calmed down. Obviously, the damage is still done and I still get some issues, but I hardly get any more bleeds."

Kin believes his experience of enlightenment is not unique and that others with haemophilia could also attain it - though he hopes the younger generation won't have to endure the suffering he did. It has left him with a positive outlook about living with haemophilia. He would welcome a cure, if there ever is one, but he's grateful for the experiences he's had and what he's learned. What, then, would he say to the parents of a newly diagnosed child?
"I would say to be optimistic. He's going to have a very normal life, as long as you just be aware of his condition, give him the best treatment available. Don't worry, everything is going to be fine."

\section{ACKNOWLEDGEMENTS}

The authors have advised no interests that might be perceived as posing a conflict or bias.

Informed consent has been obtained from the individual reported in this article.

HOW TO CITE THIS ARTICLE:

Chaplin S. Kin Kam: resilience and enlightenment. J Haem Pract 2019; 6(1:suppl): S20-S23. https://doi.org/10.17225/ jhp00133.

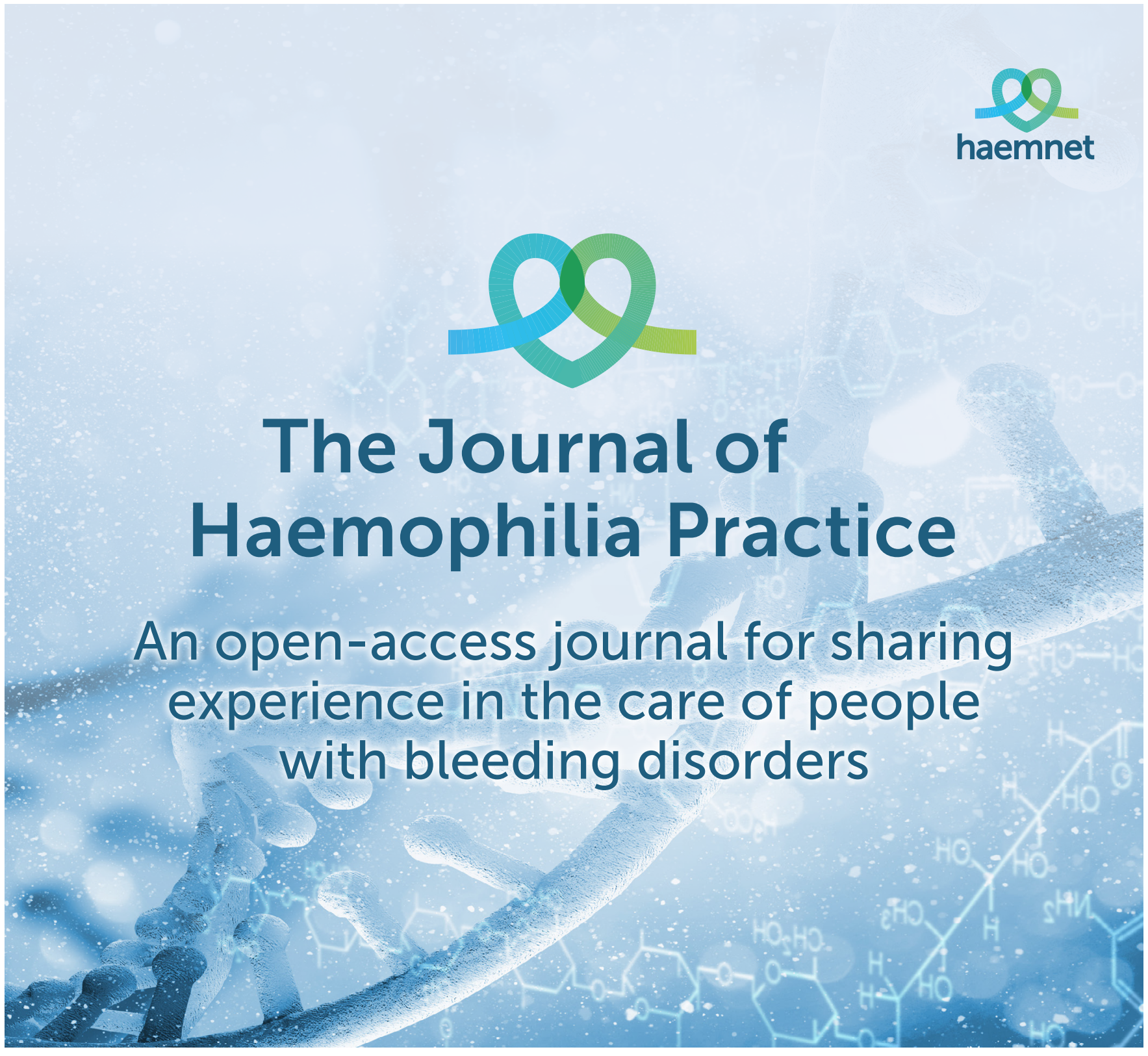

